\title{
Interaction between Body-swapping and Time-travel in the Movie "Your Name"
}

\author{
Hui Feng * \\ King's College London, Strand, London, UK, WC2R 2LS, UK \\ *fenghui8454@gmail.com
}

\begin{abstract}
In this work, I examined different perspectives on the film Your Name, accompanying these notions by the theme of gender opposition and its relation to the ideas of body swap and time travel. The main conclusions are drawn as follows: The concept of 'body swap' in Your Name give 'time travel' a new definition. It helps the two characters to have recognition to their identities. Gender stereotypes in Japanese lead to the protagonists being questioned because of body exchange, which promotes the growth of the role. Hence, in Your Name, the idea of body swap does not only refer to gender and identities or time swap. It is the exchange from environments to characters' mental state to traditions, Shinkai motivates the audiences to have a transpositional consideration.
\end{abstract}

Keywords: Your Name; Japanese Culture; Gender; Identity.

\section{Introduction}

In the film, Your Name (Makoto Shinkai, 2016), the concept of time travels blends beautifully with the Japanese culture and traditions. Makoto Shinkai uses the idea of 'body swap' to renovate the idea of time travel, in addition to utilizing it to portray the relationship between humans, nature, gender and love. In Your Name there's no intention of criticism nor sarcasm of any social problem. Instead Shinkai has knitted his ideas together to let the spectator see, listen and experience the picturesque natural scenery of the film's setting, as well as to feel the attraction between characters and hence, allowing for the spectator to reflect upon themselves. In this essay, I will examine different perspectives on the film, accompanying these notions by the theme of gender opposition and its relation to the ideas of body swap and time travel—which I position to be central in the film.

This essay will focus on three topics. First: how time and the 'body swap' in the Your Name creates a binary opposition between tradition and modernity. I would argue that this is the reason why the two deuteragonists, that Shinkai has created, are completely different-the two possess different backgrounds and ideologies, seeking change in their life, with "god" hearing them and tying the two together. Secondly, the essay will discuss the difference portrait of city and countryside in the film. On an additional note: this thematic element reoccurs in Shinkai's films, such as The Garden of Words and 5 Centimeters per Second, the director uses the subject to complement the sentiments of human and sublime it to a higher perspective. As my third topic, I will be looking at gender roles throughout the modern history of Japan, particularly focusing on how the linguistic genderization within Japanese language effects gender performance in Japanese society. Furthermore, this essay will investigate gender identity and its interaction with time and space, giving a glance into Shinkai's worldview that he tries to present in Your Name.

\section{The Clash between Traditions and Modernity}

In Your Name, Shinkai uses narration to describe the traditions which were carried down in Mitsuha Miyamizu's (Mone Kamishiraishi) family. The director also employs it to establish how the faith into the ancient god twisted time and formed the miracle of the soul exchange. Japanese Shinto religion is polytheistic, specifically it focuses on the concept of "Yaoyorozu no kamigami [1]: the eight million deities". Per this belief system, in Japan, Gods (Kami) are everywhere, watching human behaviors in daily life. For example: there are major gods such as the "Amaterasu-ōmikami" [2] who holds the most powers and is in charge of the other deities. "The Inari Okami" [2], kami of a fox, that takes care of rice and fertility. There are also minor gods, such as "Ebisu" [2], who represent 
happiness and luck. However, there are also many kami that are not as popular, but they exist in stories, and some people believe in them. They could only be known of in particular areas due to different customs carried down by the families residing there. One of these kami is "Yama-no-Kami" [2]- the god of the mountain. Each mountain in Japan has a different Yama-no-Kami. People that live on or near the mountain, or even ones who happen to pass through the area, need to praise the Yamano-Kami so that they can receive grace from the mountain and pray for their safety. Hence, people who live near the mountain hold the responsibility to take care off and tribute the Yama-no-Kami's shrine.

Moreover, in Japanese culture, anything could be God as long as there's faith in it. To illustrate: there is the existence of "tsukumogami" [3], which are also called the "tool kami". The term often refers to the kami who are 'born' from things, so to speak. A tool, that possesses a special meaning to its owner, may receive its personality as a tsukumogami after 100 years. Unlike the prior mentioned well-known gods, these small kami will be forgotten and disappear if no one remembers them and maintains their Jinja and traditions surrounding them.

Relating to Your Name, the Miyamizu family carries the responsibility to maintain the Miyamizu Jinja (Shrine) and to keep on the traditions left by their ancestor a thousand years ago. The faith of the Miyamizu family to God is in the "Musubi" - knotting, with one of the family's traditions is to knot colorful threads of string together. In the film, its importance is highlighted through dialogue, such as in the instance where Mitsuha's grandma tells Taki Tachibana (the film's other protagonist, voiced by Ryunosuke Kamiki) that Musubi is the art of God and the representation of time itself- thus emphasizing its value as a traditional practice. As a custom, the practice is also important as it connects God and people. In the film this is expressed through the following explanation of Musubi: "The threads twist, tangle, unravel and connect again, "Musubi" --That's time". Through the relating this tradition to the body swap, by merging the above elements into one cohesive concept, it gives the time travel an explanation. The time was twisted due to god's power, with the thread rope given to Taki by Mitsuha three years ago serving as a connection between the two characters, that ignores time difference and any scientific explanation. Additionally, it gives the two characters a chance to step in a completely different life.

In addition to the above, the film relates tradition to gender roles. Mitsuha is from a family carried with long lasting traditions that relate closely to the film's small town (Itomori) setting's history. Due to this fact, she grew up practicing these traditions. However, Mitsuha feels embarrassed to be seen practicing these traditions by her more 'modern' peers. She was embarrassed to have been seen by her classmate while making kuchikamizake (a type of chewed wine). Moreover, she felt tired of her life as other girls laughed at her and held prejudices against her family's manner of living. In contrast, Taki is a boy who grew up in a modern city. He has zero knowledge of the small-town customs. The drastic difference between their lives is what leads to the character's responses to the new environments that surround them once they switch bodies. Mitsuha, as Taki, is amazed by the modern city and life in Tokyo, while Taki, in Mitsuha's body, liked the story told by Mitsuha's grandma about the kuchikamizake.

Furthermore, Your Name also dissects the notion that in the highly modernized world traditions are seen as something to be forgotten and left in the past. This is demonstrated in the film through Mitsuha's father's behavior. Specifically: he leaves his house, abandons priesthood and instead chooses to go into politics and becomes the town's mayor. Despite his powerful position, he does not give much attention to his daughter and thought that the Miyamizu's woman had wired mental problems revolving around 'dreams' of other people's life. However, the traditions saved five hundred people's life. The kuchikamizake that served to God represents a half of Mitsuha. It serves as the key between life and death. The threads that represent time connect the two characters and gives them a second chance to twist the destiny.

I would argue that through employing the concept of body swapping in Your Name, Shinkai has not given a particular statement that would take the side of tradition or modernity. Although it is the tradition, and faith that generated the miracle of the body swap and saved the town. the body swap 
also gave Mitsuha the opportunity to step into the modern city, leaving her monotonous life to meet new people. Most importantly, meeting Taki and the experiences in the cities opened a new vision for Mitsuha and made her more confident and stand up to her father and persuade him to change his mind and worldview. This supports the idea that in Your Name traditions and modernity exist in an almost symbiotic relationship- mutually benefiting each other. Rather than focusing on the outcome of the clash between the two, Shinkai shows how the clash between traditions and modernity forms a miracle.

\section{Portrayal of Nature and Countryside}

In Shinkai's films, there are massive paintings and narration on nature, which contributes to the buildup of the narrative and setting off the audience' emotions. In Your Name, Shinkai creates an apparent contrast between the two environmental spaces- these being the countryside and the city. Shinkai sets Taki in the Tokyo, the highly developed city, whilst putting Mitsuha in Itomori, a small town far from the city and with simple facilities and a rustic lifestyle. Within this framing, the body swap not only gave the two characters a chance to exchange genders but also granted them an opportunity to experience a different life. In the film, living Environment is linked close to the characters' lives. To start this thread of argument with the analysis of Itomori: Shinkai presents it as an isolated, beautiful small town that forms after the impact of a comet a thousand years ago. Due to this, the landscape of Itomori is unique, as the village is built beside the meteor crater, with the rich soil and mountains, in addition to the aforementioned unique geographical position, form Itomori's beautiful natural scenery. However, despite this idealized aesthetics, the film also portrays the village and its residents as being isolated and underdeveloped.

Whereas, Tokyo is a highly developed city that contains 13859764 inhabitants (December 2018).[4] The film portrays them as living at a fast pace, high pressure, and diverse life. Comparing to the small town Itomori- that contains only 500 people- the difference striking, which amazes Mitsuha when she swaps with Taki. To express the contrast, Shinkai uses fast-paced editing accompanied with stirring music to portray Tokyo. On the other hand, he employs long shots, of long duration, to depict the small town, with the difference between the two illustrating to the audience the clash of two different life paces. However, as is the case with tradition and modernity, Shinkai does not show partiality to either the city setting or the town. He uses slow panning shots and long takes to express the peacefulness of the natural sceneries, while using time-lapse photography to represent the busy city. For both, he uses bright colors to convey their beauty- even if it is from the different perspectives.

Shinkai does not aim to create a sense of "isolation in the big city" nor the sense of "dislocation" [5] due to the fast development. Neither does he criticize the indifference of city inhabitants of humanity. On the contrary, the City and the Countryside in the film Your Name serve to complement each other- just like the film's deuteragonists. The city widened Mitsuha's horizon and made her yearn for the splendid city life, while the countryside gave Taki a break from his pressured life and made him remember the value of nature. To conclude the second topic: in Your Name, Shinkai portrays City and Countryside as a representation of Mitsuha and Taki. He expresses the beauty of both landscapes through different compositions and camera movements, in addition, to conveying the idea of coexisting of man-made materials and nature.

\section{Genderization of Speech in Japanese}

Lastly, the essay will discuss how the grammatical gender in Japanese is tied to the gender exchange associated with the body swap. In Japanese, there are many social "rules" employed when speaking. One of the most important 'rules' is concerning the usage of honorific language, which is also known as Keigo (Honorific speech in Japanese). Honorific language is used to show politeness and respect to one another. Particularly it is used to refer to people that are older than the speaker, or with higher qualifications or higher social status than them. For example: honorifics are employed 
while speaking to parents, teachers, working partners, or bosses, etc... Additionally, they are used to address a person that the speaker is meeting for the first time. Honorific language can leave a good impression to the others and make them feel respected. In addition to the usage of honorific language in daily life, there's also gendered language structures, as well as gender-based honorific language. In this section, I will talk about how gendered language and honorific language are affected by the body swap in Your Name.

In Japanese, name given to feminine form of the language is "joseigo" (women's language) and name for the male language is called "danseigo" (men's language). Joseigo makes women sounds softer, polite and with little hesitance, whereas due to their different vocabularies, danseigo sounds relatively abrupt compared to joseigo. Take self-expression as an example: the Japanese have different ways to express 'self' (similarly to the 'I' pronoun in English) according to joseigo and danseigo. For example, the female expression for 'self' are: "atakushi" and "atashi". The male expression for "self" uses "boku" and "ore". This results in pronounced differences while speaking in the first person- as is exhibited by Mitsuha and Taki's speech. This means that when Mitsuha and Taki swap bodies, the dramatic effect appears larger not only through the change of characters' behavior but also through the switch of the gendered language.

As was referenced in the first section, Mitsuha is a character with a sensitive heart. Mitsuha does not express herself out, though she still yearns for a change. She wants "to live someone else's life." Hence, after the body swap happened, with Taki in Mitsuha's body, 'Mitsuha' appears wired in her friends' eyes. She looks more confident and speaks free for 'herself.' Since Taki is not constrained by Mitsuha's concerns, he stands up against Mitsuha's classmates; he speaks straightforwardly to people and releases himself as 'Mitsuha.' Since no one knows Taki in the small town, he does not need to be restricted by the pressures he faced in the city, he behaves his true self and speaks with danseigo. For example, calling himself "ore" in Mitsuha's body and ending a sentence with "ze", "yo", "na" (male's final sentence particles). Their usage makes 'Mitsuha' sounds less polite and more abrupt and forceful- meaning that when Mitsuha returns to her body, she feels embarrassed. However, after her friends inform her that they liked the "Wired, cool Mitsuha", because she's confident and brave, Mitsuha begins to change herself. She becomes more straightforward to her inner-self and finally stands up to her father- persuading him to evacuate the town, saving the lives of five hundred people in the process.

On the other hand, Taki is a boy that tries to act 'cool' in Tokyo. He is quite independent and is also an organized individual. He writes journals and notes every day and has several part-time jobs. However, he can't handle his feelings towards Okudera Miki (Taki's colleague at his part-time job in the restaurant, voiced by Masami Nagasawa). Taki likes Miki, but he doesn't know how to express himself and take a step forward. This aspect of his character results in Mitsuha also breaking free when she swapped into Taki's body. She enjoyed going to the Café with Taki's friend, and does not hold Miki at a distance. Furthermore, when a scamp scratched Miki's skirt, Mitsuha helps her mend it. This action didn't irritate Miki, in contrast, the feminine behavior of 'Taki' and the use of joseigo (for example ending a sentence with "wa", "no", "kashira") made Mike feel that Taki is a cute boy speaks in a soft voice. When Taki returns to his body, he found himself having made a big progress with Miki. Moreover, the body swap made Taki became "warm-hearted" as well- he starts to care more about his relationship with his friends and his emotions towards Mitsuha.

Additionally, the use of gender honorific languages enlarges the effect of body swap and identities. When a female, such as Mitsuha, uses danseigo, it eradicates the stereotypes of "softness," "hesitance" that society imposed on the woman while speaking. It makes her sounds more confident and less restricted. In turn, when a male, like Taki, uses joseigo, it softens his expressions, making them sounds less stubborn and rude. To summaries: the body and language swaps help to remove gender stereotypes and contributes to the characters' growth. 


\section{Conclusion}

In conclusion, Shinkai Makoto uses the concept of 'body swap' in Your Name to give 'time travel' a new definition. The thread connects time and relations while the modern knowledge saved people's life. Most importantly, it helps the two characters to have recognition to their identities. Moreover, gender stereotypes that occur in Japanese, on a linguistic level, are questioned as a result of the body swap- thus contributing to the characters' growth. Hence, in Your Name, the idea of body swap does not only refer to gender and identities or time swap. It is the exchange of everything, from environments to characters' mental state to traditions, Shinkai motivates the audiences to have a transpositional consideration, which I would argue is one of the most beautiful traditions that should never be forgotten.

\section{References}

[1] Ashkenazi, M. (2003). Handbook of Japanese mythology. ABC-CLIO. Davis, Frederick Hadland. Myths \& Legends of Japan. Courier Corporation, 1992.

[2] Reider, N. T. (2009). Animating objects: Tsukumogamiki and the medieval illustration of Shingon truth. Japanese Journal of Religious Studies, 231-257.

[3] Statistics Department, General Affairs Bureau, Tokyo Metropolitan Government. (2019) "Tokyo population (estimated)." Toukei.metro.tokyo.jp. Accessed January 07, 2019.

[4] Lippit, S. (2002). Topographies of Japanese modernism. Columbia University Press.

[5] Weit, Dinette van der. (2018) "The Expression of Linguistic Stereotypes on Gender: A Comparison Between the Japanese Animated Movie "Kimi no Na Wa" and the English Dubbed-Translated Movie "Your Name"." Master's thesis, Available from Leiden University thesis database. 